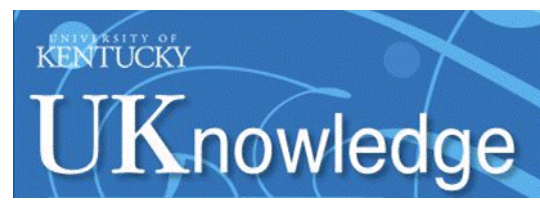

University of Kentucky

UKnowledge

\title{
Comparison of Lumbo-Pelvic Kinematics During Trunk Forward Bending and Backward Return Between Patients with Acute Low Back Pain and Asymptomatic Controls
}

\author{
Iman Shojaei \\ University of Kentucky, shojaei.iman@gmail.com \\ Elizabeth G. Salt \\ University of Kentucky, elizabeth.salt@uky.edu \\ Quenten L. Hooker \\ University of Kentucky, quenten.hooker@uky.edu \\ Linda R. Van Dillen \\ Washington University in St. Louis \\ Babak Bazrgari \\ University of Kentucky, babak.bazrgari@uky.edu \\ Follow this and additional works at: https://uknowledge.uky.edu/cbme_facpub \\ Part of the Biomechanics Commons, and the Biomedical Engineering and Bioengineering Commons \\ Right click to open a feedback form in a new tab to let us know how this document benefits you.

\section{Repository Citation} \\ Shojaei, Iman; Salt, Elizabeth G.; Hooker, Quenten L.; Van Dillen, Linda R.; and Bazrgari, Babak, \\ "Comparison of Lumbo-Pelvic Kinematics During Trunk Forward Bending and Backward Return Between \\ Patients with Acute Low Back Pain and Asymptomatic Controls" (2017). Biomedical Engineering Faculty \\ Publications. 32. \\ https://uknowledge.uky.edu/cbme_facpub/32
}

This Article is brought to you for free and open access by the Biomedical Engineering at UKnowledge. It has been accepted for inclusion in Biomedical Engineering Faculty Publications by an authorized administrator of UKnowledge. For more information, please contact UKnowledge@lsv.uky.edu. 


\section{Comparison of Lumbo-Pelvic Kinematics During Trunk Forward Bending and Backward Return Between Patients with Acute Low Back Pain and Asymptomatic Controls}

Digital Object Identifier (DOI)

https://doi.org/10.1016/j.clinbiomech.2016.12.005

Notes/Citation Information

Published in Clinical Biomechanics, v. 41, p. 66-71.

(C) 2016 Elsevier Ltd. All rights reserved.

This manuscript version is made available under the CC-BY-NC-ND 4.0 license https://creativecommons.org/licenses/by-nc-nd/4.0/.

The document available for download is the author's post-peer-review final draft of the article. 
Published in final edited form as:

Clin Biomech (Bristol, Avon). 2017 January ; 41: 66-71. doi:10.1016/j.clinbiomech.2016.12.005.

\title{
Comparison of Lumbo-Pelvic Kinematics during Trunk Forward Bending and Backward Return between Patients with Acute Low Back Pain and Asymptomatic Controls
}

\author{
Iman Shojaei ${ }^{1}$, Elizabeth G Salt ${ }^{2}$, Quenten Hooker ${ }^{3}$, Linda R Van Dillen ${ }^{4}$, and Babak \\ Bazrgari ${ }^{1}$ \\ ${ }^{1} \mathrm{~F}$. Joseph Halcomb III, M.D. Department of Biomedical Engineering, University of Kentucky, \\ Lexington, KY 40506, USA \\ ${ }^{2}$ College of Nursing, University of Kentucky, Lexington, KY 40506, USA \\ ${ }^{3}$ Department of Kinesiology and Health Promotion, University of Kentucky, Lexington, KY 40506, \\ USA \\ ${ }^{4}$ Program in Physical Therapy, Department of Orthopedic Surgery, Washington University School \\ of Medicine, St. Louis, MO 63108, USA
}

\section{Abstract}

Background-Prior studies have reported differences in lumbo-pelvic kinematics during a trunk forward bending and backward return task between individuals with and without chronic low back pain; yet, the literature on lumbo-pelvic kinematics of patients with acute low back pain is scant. Therefore, the purpose of this study was set to investigate lumbo-pelvic kinematics in this cohort.

\begin{abstract}
Methods-A case-control study was conducted to investigate the differences in pelvic and thoracic rotation along with lumbar flexion as well as their first and second time derivatives between females with and without acute low back pain. Participants in each group completed one experimental session wherein they performed trunk forward bending and backward return at selfselected and fast paces.
\end{abstract}

Findings-Compared to controls, individuals with acute low back pain had larger pelvic range of rotations and smaller lumbar range of flexions. Patients with acute low back pain also adopted a slower pace compared to asymptomatic controls which was reflected in smaller maximum values for angular velocity, deceleration and acceleration of lumbar flexion. Irrespective of participant group, smaller pelvic range of rotation and larger lumbar range of flexion were observed in younger vs. older participants.

Corresponding address: Babak Bazrgari, F. Joseph Halcomb III, M.D. Department of Biomedical Engineering, University of Kentucky, 514E Robotic and Manufacturing Building, Lexington, KY 40506, USA, Phone: (859) 257-1379. babak.bazrgari@uky.edu. Fax: (859) 257-1856.

Publisher's Disclaimer: This is a PDF file of an unedited manuscript that has been accepted for publication. As a service to our customers we are providing this early version of the manuscript. The manuscript will undergo copyediting, typesetting, and review of the resulting proof before it is published in its final citable form. Please note that during the production process errors may be discovered which could affect the content, and all legal disclaimers that apply to the journal pertain. 
Interpretation-Reduced lumbar range of flexion and slower task pace, observed in patients with acute low back pain, may be the result of a neuromuscular adaptation to reduce the forces and deformation in the lower back tissues and avoid pain aggravation.

\section{Keywords}

Acute low back pain; Forward bending and backward return; Lumbo-Pelvic Kinematics; Age and motion pace effects

\section{INTRODUCTION}

Low back pain (LBP) has been suggested to be the leading cause of disability, ahead of 290 other health related conditions (Buchbinder et al., 2013). In the United States $~ 80 \%$ of people are affected by LBP at some point during their lifetime; with an estimated annual healthcare expenditure of $\sim \$ 100$ billion (Hart et al., 1995; Katz, 2006). The lack of clarity in mechanisms driving pain presents challenges to the management of LBP. In only $~ 10 \%$ of LBP cases (i.e., specific LBP) the pain can be related to severe spinal pathology such as infection or tumor (Krismer and Van Tulder, 2007).

The lower back mechanical environment, specifically forces and deformations experienced by lower back tissues, has an important causal role in occurrence of LBP (Adams et al., 2006; Marras, 2000); thus, a developed understanding of differences in the lower back mechanical environment between individuals with and without LBP is imperative to characterize the mechanisms driving various types of LBP. Although studies have been conducted to delineate such differences, there are limitations to these studies. Direct in-vivo assessment of the lower back mechanical environment is not currently possible due to technical limitations, and ethical considerations associated with the use of the existing measurement techniques (Ledet et al., 2005; Winkelstein et al., 2002). Instead, indirect invivo measures of the lower back mechanical environment, like trunk kinematics and electromyography of trunk muscles, have been used by researchers (Cholewicki et al., 1995; Granata and Marras, 1993; Kim et al., 2013; McClure et al., 1997; Wong and Lee, 2004). These indirect measures have also been used by clinicians to assess the patient's status and guide the treatment (Carpes et al., 2008; Rittweger et al., 2002; Scannell and McGill, 2003). Findings from studies involving indirect measures of the lower back mechanical environment, particularly kinematic measures, have considerable variability and are not conclusive. Several studies have reported restrictions on the relative contribution of lumbar flexion to trunk rotation in patients with LBP vs. controls (Porter and Wilkinson, 1997; Wong and Lee, 2004). In contrast, other studies have found no differences or larger contribution of lumbar flexion to the forward bending in a LBP cohort (McClure et al., 1997). The reason for such inconsistency in results may be in part due to differences in the clinical history, LBP subtypes and personal characteristics of the participants. It has been reported that in only $54 \%$ of earlier studies of lumbo-pelvic kinematics were the patient and control groups comparable for age, gender and body mass index (BMI) (Laird et al., 2014). Furthermore, most of prior studies included patients with chronic LBP and it is not clear whether their finding can be generalized to patients with acute LBP. Although only $10 \%$ of patients with acute LBP develop chronic LBP (Andersson, 1999; Carey et al., 2000; 
Majid and Truumees, 2008; Waddell, 2004), treatment of LBP has been suggested to be more effective before the chronic stage (Waddell and Burton, 2001).

The objective of this study was to investigate differences in the lower back mechanical environment, using measures of trunk kinematics, between females with and without acute LBP. Although participants' ages were comparable between the two groups in our study, we included age as an independent variable to further explore any group by age interaction. We included the age-related analysis because of our recent findings of age-related differences in lower back biomechanics (Shojaei et al., 2016; Shojaei et al., 2015b; Vazirian et al., 2015). We also investigated the effects of task pace (i.e., fast versus self-selected) on lower back kinematics. We hypothesized that, in an effort to reduce the forces and deformation in the lower back tissues, and hence avoid pain aggravation due to mechanical stimulation, patients with acute LBP would display reduced lumbar range of flexion compared to the asymptomatic controls during the forward bending and backward return task. We further hypothesized that such reduction of lumbar flexion in patients would affect the task performance, reflected in smaller thoracic range of rotation, or/and result in larger compensatory pelvic range of rotation. We similarly hypothesized that patients would make an effort to decrease the forces and deformations in their lower back tissues by adopting a slower pace as compared to asymptomatic controls that would be reflected in smaller values of the maximum angular velocity, deceleration and acceleration of lumbar flexion. Whether the hypothesized differences between patients and controls would be magnified with aging (i.e., interaction of group and age) was unclear and left as an exploratory objective of this study.

\section{METHODS}

\section{Study Design}

A case-control study design was used wherein patients with acute LBP (health care provider diagnosed LBP $\leq 3$ months) were recruited to complete a set of experimental procedures that had been used in a baseline study involving asymptomatic individuals between 20 and 70 years old (Shojaei et al., 2015a; Vazirian et al., 2015). Upon completion of data collection from the patients with LBP, the data from all participants in the baseline study who were gender matched and were within the same age range (i.e., 40-70 years old) were extracted for comparison with the data collected from the patients.

\section{Participants}

The patients with acute LBP were referred to the study by their primary physician, whereas the asymptomatic controls were recruited via advertisement. The final sample included a group of 19 asymptomatic subjects (controls) and a group of 19 patients with acute LBP (cases). To minimize the effects of gender on the mechanical behavior of the lower back (Nachemson et al., 1979; Shojaei et al., 2016; Sullivan and Dicknison, 1994) and considering that the incidence of LBP is higher among females (Manchikanti, 2000), we only recruited female participants in this study and accordingly only used data obtained from females from the baseline study. There were no age, stature, body mass, or BMI differences (Table. 1) between the two groups ( $\mathrm{p}=0.05$ ). Exclusion criteria for asymptomatic controls 
were any history of LBP, self-reported musculoskeletal disorders or other medical conditions that might have substantially influenced the experimental results (Shojaei et al., 2015a; Vazirian et al., 2015). All asymptomatic controls also reported engaging in regular, moderate levels of physical activity. Patients with acute LBP (e.g., $\leq 3$ months) were excluded if they had significant cognitive impairment, intention to harm themselves or others, or substance abuse (Borson et al., 2000; Brown and Rounds, 1994; Ewing, 1985; Radloff, 1977). All participants in these studies completed an informed consent procedure approved by the University of Kentucky Institutional Review Board before any screening procedure.

\section{Experimental Procedures}

Participants completed two trunk forward bending and backward return tasks while standing on the center of a force platform (AMTI, Watertown, MA). During the first task participants were instructed to stand in an upright posture for five seconds, bend forward using a selfselected pace to reach their maximum trunk rotation (without excessively aggravating their LBP), hold their maximum trunk rotation for 5 seconds, extend back up to the original upright position, and stand again in an upright posture for five seconds. For the second task, participants performed the same task but as fast as possible and without a pause at the maximum trunk rotation. Prior to the conduct of these tasks, the desired method of performing them, wherein knees were kept extended throughout the tasks and arms were hanged in front at full flexed posture, was demonstrated to participants by one of research personnel. All participants completed the task with a self-selected pace prior to the task with a fast pace. Each task was repeated three times. During these tasks, trunk kinematics were tracked using wireless Inertial Measurement Units (IMUs; Xsens Technologies, Enschede, Netherlands) attached superficial to the T10 and the S1 spinous process (Shojaei et al., 2015b). The sampling rate of the inertial units was $50 \mathrm{~Hz}$. Sensors placed on the T10 and the $\mathrm{S} 1$ were assumed to measure rotations of pelvis and thorax as rigid bodies whereas the difference between these two rotations (i.e., relative rotation of thorax with respect to the pelvis) was considered to represent lumbar flexion/extension as a joint.

\section{Data analysis}

The Xsens MTw ${ }^{\mathrm{TM}}$ system is a miniature wireless inertial measurement unit system incorporating 3D accelerometers, gyroscopes, magnetometers, and a barometer. We have tested the accuracy of our sensors and the reliability of using the Xsens system in our lab by a unique testing fixture (Shojaei et al., 2016) which enables us to generate known rotation with $<1$ deg accuracy. The mean (SD) accuracy of our sensors is $0.5(0.3)$ deg and the reliability of using the Xsens system in our lab, quantified using intraclass correlation coefficients, is excellent (i.e., 1.000). Using the rotation matrices extracted from the IMUs, rotation quaternions (a rotation about a unit vector $n$ through an angle $a$ for each IMU) were obtained and used to calculate the pelvic and thoracic rotations in the sagittal plane (Roetenberg et al., 2009). The initial standing posture was regarded as the reference posture. At each time point, lumbar flexion was calculated from the difference between the thoracic and pelvic rotations (Fig. 1 and Fig. 2). Angular velocity and acceleration of the lumbar spine during the fast paced tasks were obtained using a successive numerical differentiation procedure (Fig. 3). To remove high-frequency noise, specifically amplified by 
differentiating, the kinematic raw data were filtered at $6 \mathrm{~Hz}$ using a fourth order, bidirectional, Butterworth filter (Winter, 2009; Kristianslund et al., 2012).

\section{Statistical Analysis}

For each task, pelvic and thoracic ranges of rotation as well as lumbar range of flexion were extracted for statistical analyses. Specifically, range of rotation/flexion was considered to be the maximum recorded rotation/flexion with respect to its value at reference posture. The peak values of angular velocity, acceleration (i.e., increase in absolute value of velocity), and deceleration (i.e., decrease in absolute value of velocity) of the lumbar spine during the forward bending and backward return phases of the task with fast pace also were extracted for statistical analyses. For each variable, the mean value across the three trials was used. All statistical procedures were conducted in SPSS (IBM SPSS Statistics 22, Armonk, NY, USA), and in all cases a p value smaller than 0.05 was considered as statistically significant. One set of mixed-model analysis of variance (ANOVA) tests were conducted on the dependent variables of pelvic and thoracic range of rotations and lumbar range of flexion. The between subjects factors were group (with and without LBP) and age. The within subjects factor was motion pace (self-selected and fast). To be consistent with our earlier baseline study, the age factor was considered to have three levels each related to a decade of life between 40 and 70 years (i.e., 40-50, 50-60, 60-70). A second set of mixed-model ANOVA tests were conducted to test for the effects of group, age, and motion phase on peak values of lumbar angular velocity, angular acceleration, and deceleration during the as fast as possible condition. The between subjects factors were group and age. The within subjects factor was motion phase (forward bending or backward return). Significant ANOVA tests were followed by post hoc tests using Tukey's procedure.

\section{RESULTS}

\section{Thoracic range of rotation}

While there were no significant differences (Table. 2) in the thoracic range of rotation between patients $\left(104.6^{\circ}\left(13.6^{\circ}\right)\right)$ and controls $\left(99.1^{\circ}\left(13.4^{\circ}\right)\right)$, the thoracic range of rotation was larger during tasks with fast $\left(105.3^{\circ}\left(12.9^{\circ}\right)\right)$ vs. self-selected $\left(98.4^{\circ}\left(13.7^{\circ}\right)\right)$ paces. Furthermore, there was no age-related difference (Table. 2$)$ in thoracic range of rotation (4050: $99.7^{\circ}\left(12.7^{\circ}\right)$; 50-60: $\left.108.0^{\circ}\left(11.2^{\circ}\right) ; 60-70: 97.4^{\circ}\left(14.6^{\circ}\right)\right)$. There was also no significant interaction effects of independent variables on the thoracic range of rotation (Table. 2).

\section{Pelvic range of rotation}

Pelvic range of rotation was larger in patients $\left(61.6^{\circ}\left(12^{\circ}\right)\right)$ vs. controls $\left(43.4^{\circ}\left(14.5^{\circ}\right)\right)$ and was larger in tasks with fast $\left(56.7^{\circ}\left(15.2^{\circ}\right)\right)$ vs. self-selected $\left(48.3^{\circ}\left(16^{\circ}\right)\right)$ pace (Table. 2$)$. The effect of age also was significant (Table. 2) such that pelvic range of rotation was larger in the two older groups compared to the younger group (Fig. 4). There was no significant interaction effects of independent variables on the pelvic range of rotation (Table. 2) 


\section{Lumbar range of flexion}

Lumbar range of flexion was smaller in patients $\left(43^{\circ}\left(11.2^{\circ}\right)\right)$ vs. controls $\left(55.7^{\circ}\left(11.3^{\circ}\right)\right)$

and was smaller during tasks with a fast $\left(48.6^{\circ}\left(13.3^{\circ}\right)\right)$ vs. self-selected $\left(50.1^{\circ}\left(12.5^{\circ}\right)\right)$ pace

(Table. 2). The effect of age on lumbar range of flexion was significant with a smaller range of flexion in the oldest vs. youngest group (Table. 2 and Fig. 4).

\section{Lumbar angular velocity, acceleration, and deceleration during the task with fast pace}

Peak angular velocity of lumbar flexion was higher in controls $(94.7 \mathrm{deg} / \mathrm{sec}(25.9 \mathrm{deg} / \mathrm{sec}))$ than in patients $(65.5 \mathrm{deg} / \mathrm{sec}(31 \mathrm{deg} / \mathrm{sec}))$ and was higher during the forward bending $(84.7$ $\mathrm{deg} / \mathrm{sec}(33 \mathrm{deg} / \mathrm{sec}))$ vs. backward return $(78 \mathrm{deg} / \mathrm{sec}(28 \mathrm{deg} / \mathrm{sec}))$ phase of the motion (Table. 3). There was a significant three-way interaction of group $\times$ motion phase $\times$ age on lumbar angular deceleration (Table. 3). Specifically, during the forward bending phase, the effect of group was significant $(\mathrm{F}=9.5, \mathrm{p}=0.009)$ on peak lumbar deceleration of individuals in the 60-70 year old group such that the deceleration was larger in controls $\left(259.8 \mathrm{deg} / \mathrm{sec}^{2}\right.$ $\left.\left(89.2 \mathrm{deg} / \mathrm{sec}^{2}\right)\right)$ than patients $\left(137.4 \mathrm{deg} / \mathrm{sec}^{2}\left(55.2 \mathrm{deg} / \mathrm{sec}^{2}\right)\right)$ (Fig. 5). Moreover, during the backward return phase, the effect of group was significant $(F=22.5, \mathrm{p}<0.000)$ on peak lumbar deceleration of individuals in the 50-60 year old group such that the deceleration was larger in controls $\left(291.4 \mathrm{deg} / \mathrm{sec}^{2}\left(69.3 \mathrm{deg} / \mathrm{sec}^{2}\right)\right)$ than patients $\left(140.2 \mathrm{deg} / \mathrm{sec}^{2}(38.3\right.$ $\left.\mathrm{deg} / \mathrm{sec}^{2}\right)$ ) (Fig. 5). Similarly, there was a significant (Table. 3) interaction of group $\times$ motion phase $\times$ age on the lumbar angular acceleration. Specifically, for the forward bending phase of the motion, the effect of group was significant $(\mathrm{F}=5.56, \mathrm{p}=0.036)$ for individuals in the 60-70 year old group with larger lumbar acceleration in controls $\left(213.2 \mathrm{deg} / \mathrm{sec}^{2}\right.$ (73.9 $\left.\mathrm{deg} / \mathrm{sec}^{2}\right)$ ) vs. patients $\left(132.2 \mathrm{deg} / \mathrm{sec}^{2}\left(53.0 \mathrm{deg} / \mathrm{sec}^{2}\right)\right)$ (Fig. 5). Furthermore, for the backward return phase of the motion, the effect of group was significant $(F=8.95, p=0.011)$ for individuals in the 50-60 years old group with larger lumbar acceleration in controls $\left(265.3 \mathrm{deg} / \mathrm{sec}^{2}\left(79.0 \mathrm{deg} / \mathrm{sec}^{2}\right)\right)$ vs. patients $\left(148.0 \mathrm{deg} / \mathrm{sec}^{2}\left(67.7 \mathrm{deg} / \mathrm{sec}^{2}\right)\right)($ Fig. 5)

\section{DISCUSSION}

The purpose of this study was to investigate differences in the lower back mechanical environment, using measures of trunk kinematics, between a group of asymptomatic controls and a group of patients with acute LBP. The thoracic range of rotation was similar in both groups. However, the contribution of pelvic rotation and lumbar flexion to range of thoracic rotation was, respectively, larger and smaller among patients compared to controls. These findings confirmed our first hypothesis. Furthermore, as we hypothesized, patients adopted a slower pace compared to asymptomatic controls which was reflected in smaller values of the maximum angular velocity, deceleration and acceleration of lumbar flexion. While the main effect of age was significant on lumbo-pelvic kinematics with smaller pelvic rotation and larger lumbar flexion in younger vs. older population, there was not any interaction effect of group $\times$ age on lumbo-pelvic kinematics indicating that aging similarly affects individuals with and without acute LBP.

A fair number of studies have investigated the effects of LBP on lumbo-pelvic kinematics, however, only a few have included patients with acute LBP (Wong and Lee, 2004). Our finding of smaller lumbar range of flexion in patients with acute LBP is consistent with 
those reported by Wong and Lee (2004). However, due to different methods of measurement between the two studies, we were not able to compare pelvis range of rotation, though, they reported smaller hip flexion (vs. larger pelvis rotation in our study) in patients with acute LBP (Wong and Lee, 2004). Considering a population with comparable personal characteristics and accounting for the effects of age and motion pace, our findings demonstrated clear differences (Table. 2) in lumbo-pelvic kinematics between individuals with and without acute LBP. In studies with a more heterogeneous sample where the confounding variables are not considered in the analysis, it is not clear whether the reported differences in kinematics were purely due to LBP or other variables such as personal or task characteristics (Intolo et al., 2009; McGregor and Hughes, 2000; Shojaei et al., 2015b; Sullivan and Dicknison, 1994). Therefore, our findings might have better isolated and highlighted the likely LBP-related differences in lower back kinematics.

The smaller contribution of lumbar flexion to thoracic rotation, adopted by patients with acute LBP, may be an attempt to reduce tension in posterior elements of the ligamentous spine (posterior longitudinal ligaments, posterior aspect of annulus fibrosus, and facet capsule) that have embedded pain sensitive nerve endings (Adams et al., 2006). These results are also consistent with the reported persistent activation of the lumbar erector spinae muscles and the absence of flexion-relaxation phenomenon among patients with LBP which has been suggested to be an attempt to stabilize injured spinal structures and protect them from further injury (Colloca and Hinrichs, 2005). In other word, smaller lumbar flexion is associated with smaller passive contribution of lower back tissues to spine equilibrium; a difference in contribution that should be offset by increase in active muscle contribution.

The smaller lumbar contribution in patients with LBP compared to controls did not affect the task performance; both groups displayed a similar amount of thoracic rotation. The similar amount of thoracic movement was the result of using more pelvic rotation by patient with LBP compared to the controls. Large pelvic rotations impose higher shearing demands on the lower back (Shojaei et al., 2015b) and are also associated with projection of a larger shearing component of internal muscle forces on the spine (Arjmand and Shirazi-Adl, 2005). Therefore, an increased level of contact force on facet joints of the lumbar spine could be the negative cost of the adopted posture displayed by patients with acute LBP.

Earlier studies on lumbo-pelvic kinematics during forward bending and backward return mostly have been conducted under stationary conditions (imaging studies) (Jensen et al., 1994; Pearcy et al., 1984) or slow and self-selected paces (Kim et al., 2013; McClure et al., 1997; Wong and Lee, 2004). Including a faster motion pace enabled us to better delineate differences in biomechanics between people with acute LBP and asymptomatic controls. Specifically, while the thoracic rotation increased in the fast vs. self-selected pace, the lumbar flexion decreased. Such posture adoption is probably a safer strategy for reducing stress in the lower back tissues because of the viscoelastic behavior and the inertial demand of fast tasks (Bazrgari et al., 2008).

Higher order lumbo-pelvic kinematics have been suggested to be reliable objective measures of the trunk motion (Aluko et al., 2011; Kroemer et al., 1990) and can well distinguish patients with chronic LBP from asymptomatic controls (Marras et al., 1993). Similar to the 
study by Marras et al. (1993), where much larger difference was found in lumbar angular acceleration than angular velocity and flexion between patients with chronic LBP and controls (i.e., 5 degree, $49 \mathrm{deg} / \mathrm{sec}$, and $251 \mathrm{deg} / \mathrm{sec}^{2}$ differences in the respective values of lumbar flexion, lumbar angular velocity, and lumbar angular acceleration), greater differences in angular acceleration were found in the present study (i.e., $12.7 \mathrm{deg}, 29.2 \mathrm{deg} /$ sec, and $>81 \mathrm{deg} / \mathrm{sec}^{2}$ differences in the respective values of lumbar flexion, lumbar angular velocity, and lumbar angular acceleration.

Although we didn't control for intersubject variability such as pain level, LBP related disability, fear of movement, and general health status, lumbo-pelvic kinematics were clearly different between LBP patients and asymptomatic controls. However, it remains unclear whether such kinematic differences are the cause or consequence of LBP. Such a research question can be addressed in future studies through conducting longitudinal studies. The observed kinematic differences suggest likely differences in lower back biomechanics between people with acute LBP and people without LBP, however, a better understanding can be achieved regarding altered neuromuscular strategy using model based estimations of trunk muscle forces and spinal loads (Shojaei et al., 2015a). Finally, our results on agerelated differences in lumbo-pelvic kinematics were consistent with our earlier findings, however, the potential inferential errors due to small sample size should be kept in mind when interpreting these results.

\section{Acknowledgments}

This work was supported in part by the National Center for Research Resources and the National Center for Advancing Translational Sciences [UL1TR000117]. Dr. Van Dillen's contribution was supported by grant NICHD/ NCMRR R01 HD047709. The content of this manuscript is solely the responsibility of the authors and does not necessarily represent the official views of the NIH.

\section{REFERENCES}

Adams MA, Burton K, Bogduk N. The biomechanics of back pain. Elsevier Health Sci. 2006; 55

Aluko A, DeSouza PL, Peacock PJ. Evaluation of trunk acceleration in healthy individuals and those with low back pain. Int. J. Ther. Rehabil. 2011; 18(1):18-25.

Andersson GB. Epidemiological features of chronic low-back pain. The lancet. 1999; 354(9178):581585.

Arjmand N, Shirazi-Adl A. Biomechanics of changes in lumbar posture in static lifting. Spine. 2005; 30(23):2637-2648. [PubMed: 16319750]

Aure OF, Nilsen JH, Vasseljen O. Manual therapy and exercise therapy in patients with chronic low back pain: a randomized, controlled trial with 1-year follow-up. Spine. 2003; 28(6):525-531. [PubMed: 12642755]

Bazrgari B, Shirazi-Adl A, Trottier M, Mathieu P. Computation of trunk equilibrium and stability in free flexion-extension movements at different velocities. J. Biomech. 2008; 41(2):412-421. [PubMed: 17897654]

Borson S, Scanlan J, Brush M, Vitaliano P, Dokmak A. The Mini-Cog: a cognitive 'vital signs' measure for dementia screening in multi-lingual elderly. Int. J. Geriat. Psych. 2000; 15(11):1021-1027.

Brown RL, Rounds LA. Conjoint screening questionnaires for alcohol and other drug abuse: criterion validity in a primary care practice. Wis. Med. J. 1994; 94(3):135-140.

Buchbinder R, Blyth FM, March LM, Brooks P, Woolf AD, Hoy DG. Placing the global burden of low back pain in context. Best Prac. \& Res. Clin. Rheum. 2013; 27(5):575-589. 
Carey TS, Garrett JM, Jackman AM. Beyond the good prognosis: examination of an inception cohort of patients with chronic low back pain. Spine. 2000; 25(1):115. [PubMed: 10647169]

Carpes FP, Reinehr FB, Mota CB. Effects of a program for trunk strength and stability on pain, low back and pelvis kinematics, and body balance: a pilot study. J. of Body \& Mov. Therap. 2008; 12(1):22-30.

Cholewicki J, McGill SM, Norman RW. Comparison of muscle forces and joint load from an optimization and EMG assisted lumbar spine model: towards development of a hybrid approach. J. Biomech. 1995; 28(3):321-331. [PubMed: 7730390]

Colloca CJ, Hinrichs RN. The biomechanical and clinical significance of the lumbar erector spinae flexion-relaxation phenomenon: a review of literature. J. Manip. \& Phys. Therap. 2005; 28(8): 623-631.

Ewing KA. Detecting Alcoholism: The Cage Questionnaire. J. Occup. \& Envir. Med. 1985; 27(3):224.

Granata K, Marras W. An EMG-assisted model of loads on the lumbar spine during asymmetric trunk extensions. J. Biomech. 1993; 26(12):1429-1438. [PubMed: 8308047]

Hart LG, Deyo RA, Cherkin DC. Physician office visits for low back pain: frequency, clinical evaluation, and treatment patterns from a US national survey. Spine. 1995; 20(1):11-19. [PubMed: 7709270]

Intolo P, Milosavljevic S, Baxter DG, Carman AB, Pal P, Munn J. The effect of age on lumbar range of motion: a systematic review. Man. Ther. 2009; 14(6):596-604. [PubMed: 19729332]

Jensen MC, Brant-Zawadzki MN, Obuchowski N, Modic MT, Malkasian D, Ross JS. Magnetic resonance imaging of the lumbar spine in people without back pain. New Eng. J. of Med. 1994; 331(2):69-73. [PubMed: 8208267]

Katz JN. Lumbar disc disorders and low-back pain: socioeconomic factors and consequences. J. Bone Joint Surg. Am. 2006; 88(suppl 2):21-24. [PubMed: 16595438]

Kim, M-h, Yoo, W-g, Choi, B-r. Differences between two subgroups of low back pain patients in lumbopelvic rotation and symmetry in the erector spinae and hamstring muscles during trunk flexion when standing. J. Electro. \& Kin. 2013; 23(2):387-393.

Krismer M, Van Tulder M. Low back pain (non-specific). Best Prac. \& Res. Clin. Rheum. 2007; 21(1): 77-91.

Kristianslund E, Krosshaug T, Van den Bogert AJ. Effect of low pass filtering on joint moments from inverse dynamics: implications for injury prevention. J. Biomech. 2012; 45(4):666-671. [PubMed: 22227316]

Kroemer K, Marras W, Mcglothlin D, Nordin M. Towards understanding human dynamic motor performance. Ind. Ergon. J. 1990; 6:199.

Laird RA, Gilbert J, Kent P, Keating JL. Comparing lumbo-pelvic kinematics in people with and without back pain: a systematic review and meta-analysis. BMC Musc. Dis. 2014; 15(1):1.

Ledet EH, Tymeson MP, DiRisio DJ, Cohen B, Uhl RL. Direct real-time measurement of in vivo forces in the lumbar spine. The Spine J. 2005; 5(1):85-94. [PubMed: 15653089]

Leinonen V, Kankaanpää M, Airaksinen O, Hänninen O. Back and hip extensor activities during trunk flexion/extension: effects of low back pain and rehabilitation. Arch. of Phys. Med. \& Rehab. 2000; 81(1):32-37.

Majid K, Truumees E. Epidemiology and natural history of low back pain, Seminars in Spine Surgery. Elsevier. 2008; 20(2):87-92.

Manchikanti L. Epidemiology of low back pain. Pain Phys. 2000; 3(2):167-192.

Mannion AF, Junge A, Taimela S, Müntener M, Lorenzo K, Dvorak J. Active therapy for chronic low back pain: part 3. Factors influencing self-rated disability and its change following therapy. Spine. 2001; 26(8):920-929. [PubMed: 11317114]

Marras W. Occupational low back disorder causation and control. Ergon. 2000; 43(7):880-902.

Marras W, Parnianpour M, Ferguson S, Kim J, Crowell R, Simon S. Quantification and classification of low back disorders based on trunk motion. Eur. J. Phys. Rehab. Med. 1993; 3:218-235.

McClure PW, Esola M, Schreier R, Siegler S. Kinematic analysis of lumbar and hip motion while rising from a forward, flexed position in patients with and without a history of low back pain. Spine. 1997; 22(5):552-558. [PubMed: 9076888] 
McGregor AH, Hughes SP. The effect of test speed on the motion characteristics of the lumbar spine during an AP flexion-extension test. J. Back \& Musc. Rehab. 2000; 14(3):99-104.

Nachemson AL, Schultz AB, Berkson MH. Mechanical Properties of Human Lumbar Spine Motion Segments: Influences of Age, Sex, Disc Level, and Degeneration. Spine. 1979; 4(1):1-8. [PubMed: 432710]

Panjabi MM. Clinical spinal instability and low back pain. J. Elect. \& Kines. 2003; 13(4):371-379.

Pearcy M, Portek I, Shepherd J. Three-dimensional x-ray analysis of normal movement in the lumbar spine. Spine. 1984; 9(3):294-297. [PubMed: 6374922]

Porter JL, Wilkinson A. Lumbar-hip flexion motion: a comparative study between asymptomatic and chronic low back pain in 18-to 36-year-old men. Spine. 1997; 22(13):1508-1513. [PubMed: 9231971]

Radloff LS. The CES-D scale a self-report depression scale for research in the general population. App. Psych. Meas. 1977; 1(3):385-401.

Rittweger J, Just K, Kautzsch K, Reeg P, Felsenberg D. Treatment of chronic lower back pain with lumbar extension and whole-body vibration exercise: a randomized controlled trial. Spine. 2002; 27(17):1829-1834. [PubMed: 12221343]

Roetenberg D, Luinge H, Slycke P. Xsens MVN: full 6DOF human motion tracking using miniature inertial sensors. Xsens Motion Technologies BV, Tech. Rep. 2009

Scannell JP, McGill SM. Lumbar posture—should it, and can it, be modified? A study of passive tissue stiffness and lumbar position during activities of daily living. Phys. Ther. 2003; 83(10):907-917. [PubMed: 14519062]

Shojaei I, Allen-Bryant K, Bazrgari B. Viscoelastic Response of the Human Lower Back to Passive Flexion: The Effects of Age. Ann. Biomed. Eng. 2016:1-10. [PubMed: 26620776]

Shojaei I, Hendershot BD, Wolf EJ, Bazrgari B. Persons with unilateral transfemoral amputation experience larger spinal loads during level-ground walking compared to able-bodied individuals. Clin. Biomech. 2015a; 32:157-163.

Shojaei I, Vazirian M, Croft E, Nussbaum MA, Bazrgari B. Age related differences in mechanical demands imposed on the lower back by manual material handling tasks. J. Biomech. 2015b; 49(6): 896-903. [PubMed: 26556714]

Sullivan MS, Dicknison C. The Influence of Age and Gender on Lumbar Spine Sagittal Plane Range of Motion: A Study of 1126 Healthy Subjects. Spine. 1994; 19(6):682-686. [PubMed: 8009333]

Van Hoof W, Volkaerts K, O'Sullivan K, Verschueren S, Dankaerts W. Comparing lower lumbar kinematics in cyclists with low back pain (flexion pattern) versus asymptomatic controls-field study using a wireless posture monitoring system. Man. therap. 2012; 17(4):312-317. [PubMed: 22436688]

Vazirian M, Shojaei I, Tromp RL, Nussbaum MA, Bazrgari B. Age-related differences in trunk intrinsic stiffness. J. Biomech. 2015; 49(6):926-932. [PubMed: 26459489]

Waddell G. The back pain revolution. Elsevier Health Sciences. 2004

Waddell G, Burton AK. Occupational health guidelines for the management of low back pain at work: evidence review. Occup. Med. 2001; 51(2):124-135.

White AA III, Panjabi MM. The basic kinematics of the human spine: A review of past and current knowledge. Spine. 1978; 3(1):12-20. [PubMed: 347598]

Winkelstein BA, Weinstein JN, DeLeo JA. The role of mechanical deformation in lumbar radiculopathy: an in vivo model. Spine. 2002; 27(1):27-33. [PubMed: 11805632]

Winter, DA. Biomechanics and motor control of human movement. John Wiley \& Sons; 2009.

Wong TK, Lee RY. Effects of low back pain on the relationship between the movements of the lumbar spine and hip. Hum. Mov. Sci. 2004; 23(1):21-34. [PubMed: 15201039] 


\section{HIGHLIGHTS}

- The literature on trunk kinematics of patients with acute low back pain is scant

- $\quad$ Trunk kinematics in patients with acute low back pain and controls were quantified

- $\quad$ Patients had larger pelvic range of rotations and smaller lumbar range of flexions

- The adopted trunk kinematics by patients might be a strategy to avoid pain 


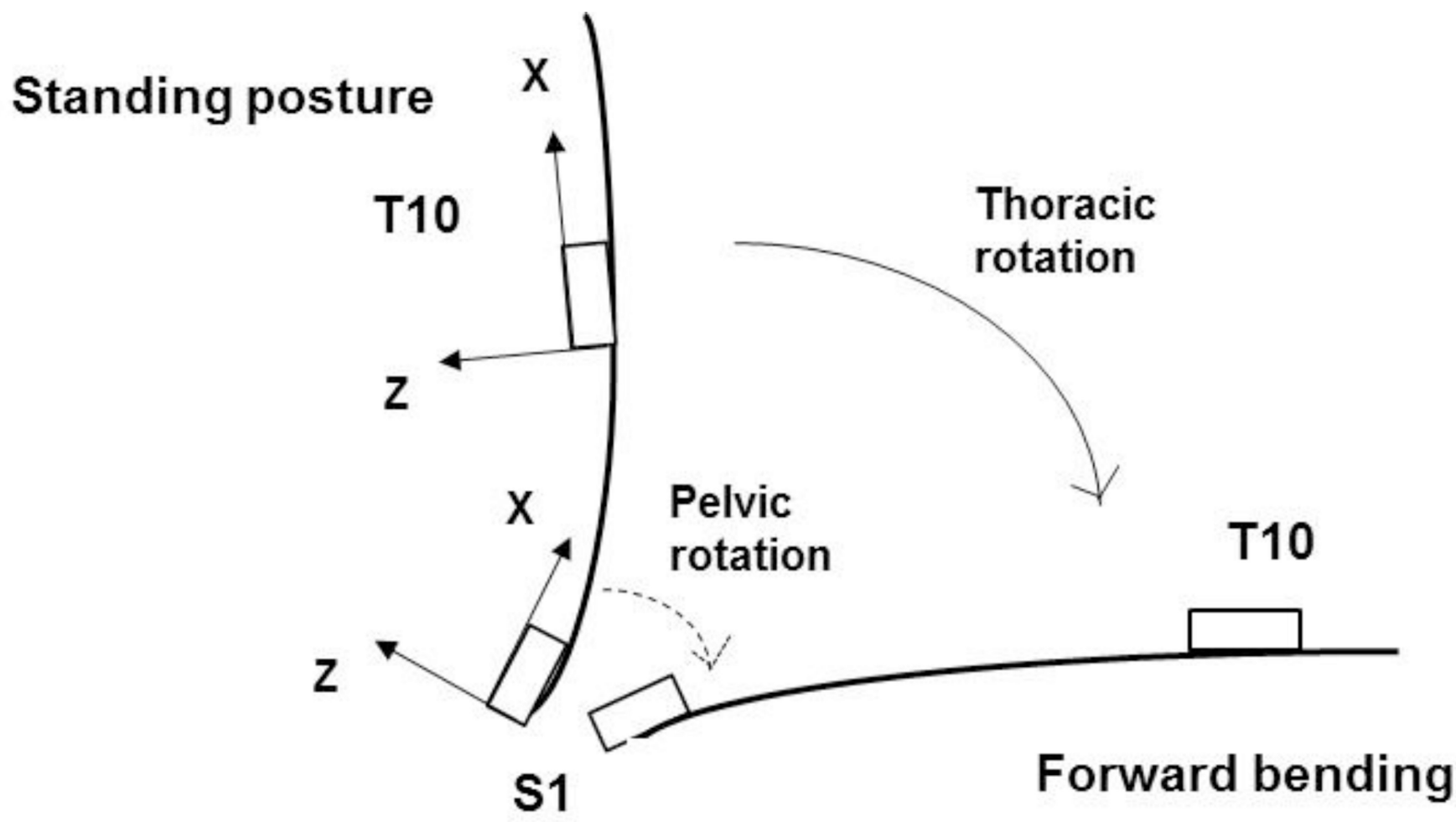

Figure 1.

Definition of the pelvic and thoracic rotations as well as the local coordinate system of IMUs. Y axis is normal to the plane (the right-hand rule). Lumbar flexion is the difference between the thoracic and pelvic rotations. 

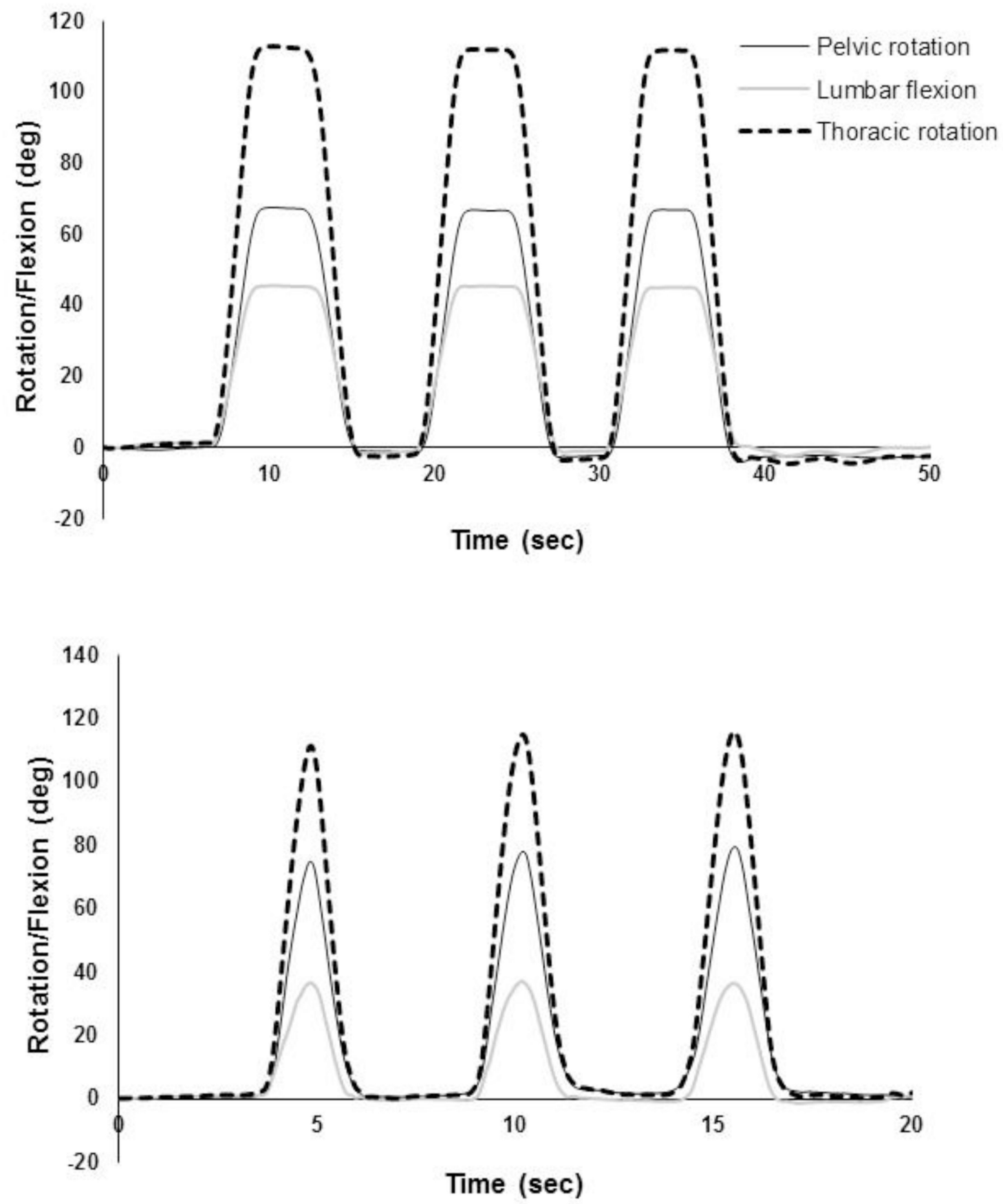

Figure 2.

Typical examples of pelvic and thoracic rotations as well as lumbar flexion for the tasks with a self-selected pace (top) and a fast pace (bottom). 

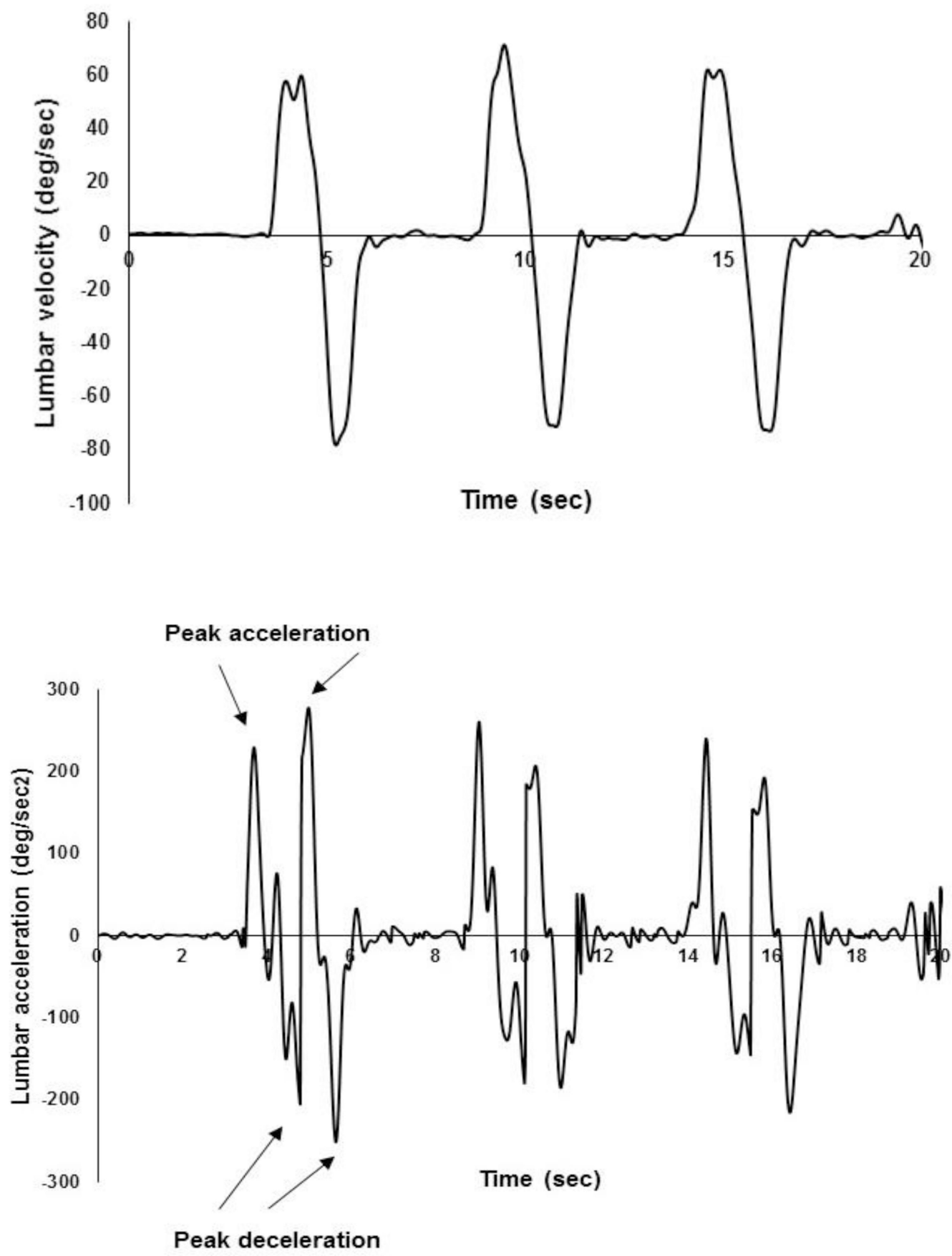

Figure 3.

Typical examples of lumbar angular velocity (top) and acceleration (bottom). To facilitate automatic extraction of maximum values for lumbar acceleration (i.e., increase in absolute value of velocity) and deceleration (i.e., decrease in absolute value of velocity), the second derivative of lumbar flexion (i.e., containing acceleration and deceleration) was obtained through the numerical differentiation of the absolute values (i.e., positive only) of lumbar angular velocity. 

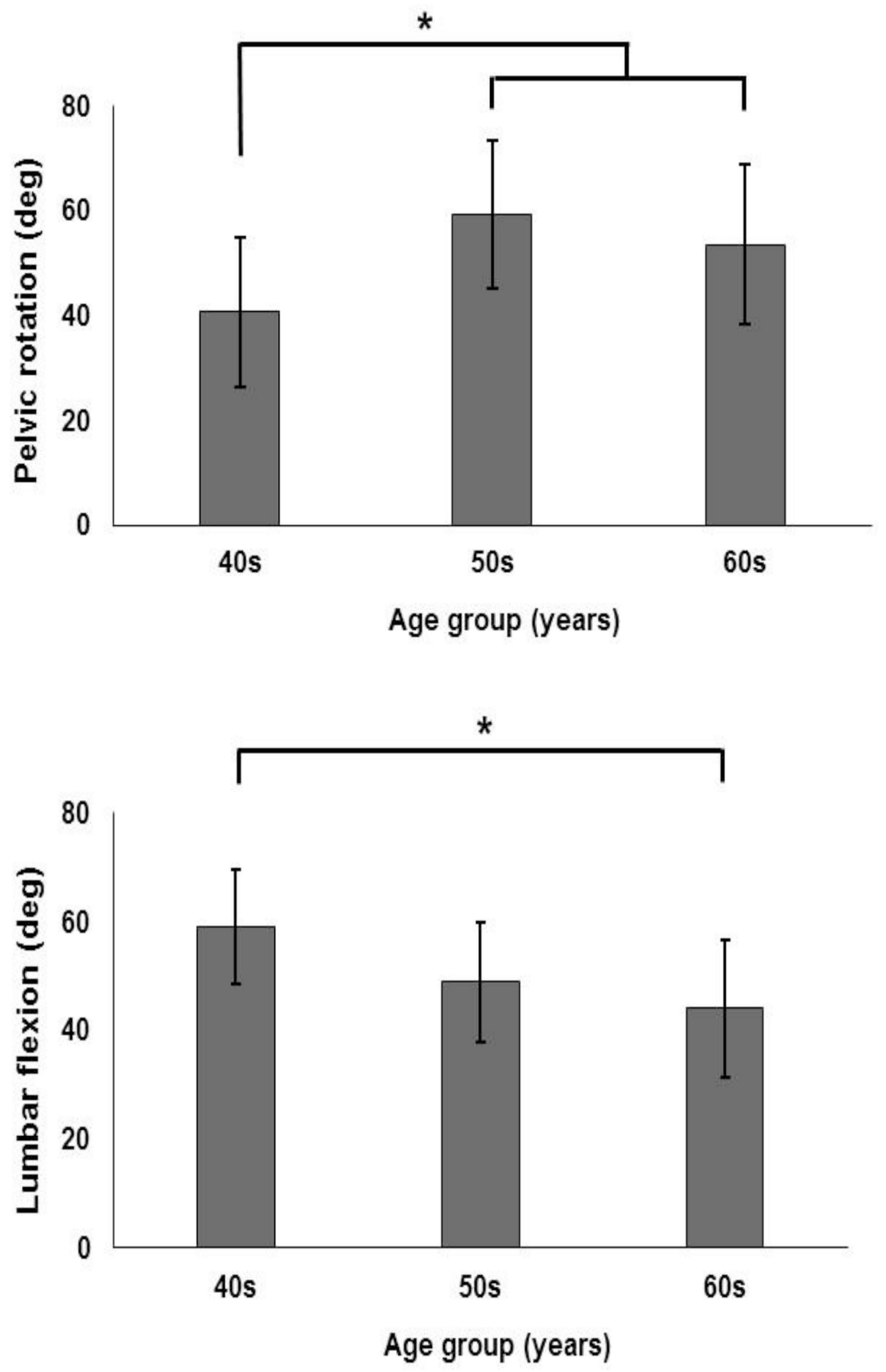

Figure 4.

Age-related differences in pelvic range of rotation (top), and lumbar range of flexion (bottom). Error bars indicate standard deviations. 

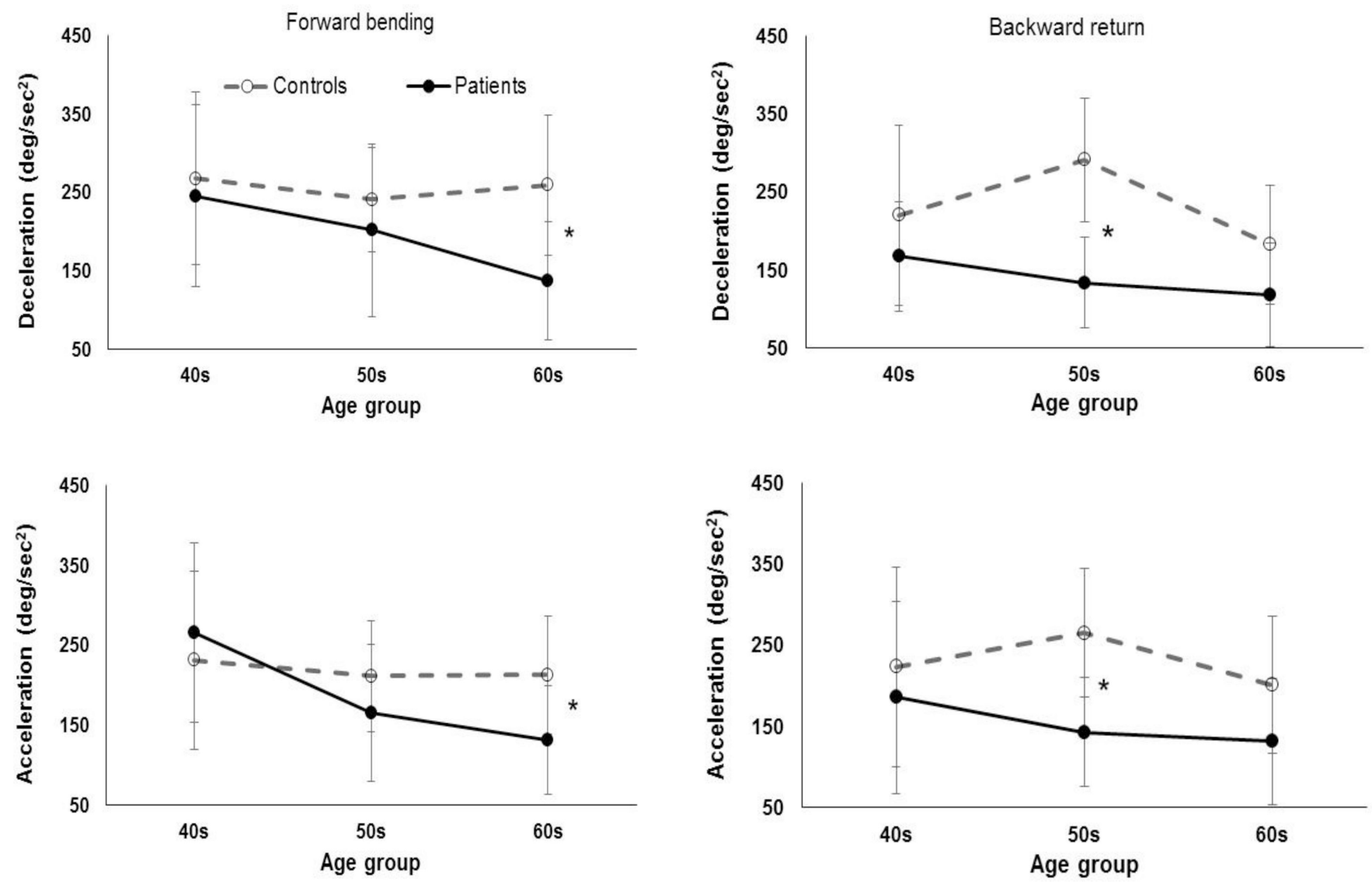

Figure 5.

The age $\times$ group $\times$ motion phase interactions in peak lumbar angular deceleration (i.e., decrease in absolute value of velocity) and acceleration (i.e., increase in absolute value of velocity). Error bars indicate standard deviations. 


\section{Table 1}

Mean (SD) participants characteristics

\begin{tabular}{|c|c|c|c|c|}
\hline Group & Controls & Patients & $\boldsymbol{t}$-value & p-values \\
\hline Age (years) & $56(9)$ & $58(9)$ & 0.723 & 0.474 \\
\hline Stature (m) & $1.64(5)$ & $1.63(7)$ & -0.592 & 0.557 \\
\hline Body mass (kg) & $70(12)$ & $76(17)$ & 1.553 & 0.130 \\
\hline BMI & $25.7(4.1)$ & $27.5(4.6)$ & 1.608 & 0.117 \\
\hline
\end{tabular}




\section{Table 2}

Summary of statistics for the effects of group (with and without LBP), motion pace (self-selected and fast) and age (40-50, 50-60, and 60-70) on pelvic and thoracic ranges of rotation and lumbar range of flexion.

\begin{tabular}{|c|c|c|c|c|}
\hline \multicolumn{2}{|c|}{} & $\begin{array}{c}\text { Thoracic } \\
\text { Rotation }\end{array}$ & $\begin{array}{c}\text { Pelvic } \\
\text { Rotation }\end{array}$ & $\begin{array}{c}\text { Lumbar } \\
\text { Flexion }\end{array}$ \\
\hline \multirow{3}{*}{ Group } & $F$ & 1.40 & 17.34 & 10.69 \\
\cline { 2 - 5 } & $p$ & 0.246 & $<\mathbf{0 . 0 0 1}$ & $\mathbf{0 . 0 0 3}$ \\
\hline \multirow{3}{*}{ Pace } & $F$ & 24.87 & 61.67 & 4.97 \\
\cline { 2 - 5 } & $p$ & $<\mathbf{0 . 0 0 1}$ & $<\mathbf{0 . 0 0 1}$ & $\mathbf{0 . 0 3 3}$ \\
\hline \multirow{3}{*}{ Age } & $F$ & 2.43 & 3.70 & 3.58 \\
\cline { 2 - 5 } & $p$ & 0.104 & $\mathbf{0 . 0 3 6}$ & $\mathbf{0 . 0 3 9}$ \\
\hline \multirow{3}{*}{ Group $\times$ Pace } & $F$ & 0.18 & 0.01 & 0.91 \\
\cline { 2 - 5 } & $p$ & 0.672 & 0.918 & 0.346 \\
\hline \multirow{2}{*}{ Group $\times$ Age } & $F$ & 0.36 & 0.15 & 0.41 \\
\cline { 2 - 5 } & $p$ & 0.700 & 0.861 & 0.666 \\
\hline \multirow{2}{*}{ Age $\times$ Pace } & $F$ & 0.84 & 0.24 & 1.19 \\
\cline { 2 - 5 } & $p$ & 0.442 & 0.789 & 0.317 \\
\hline \multirow{2}{*}{ Group $\times$ Age $\times$} \\
Pace & $F$ & 0.84 & 0.37 & 1.57 \\
\cline { 2 - 5 } & $p$ & 0.441 & 0.691 & 0.223 \\
\hline
\end{tabular}

Boldface indicates a significant effect 


\section{Table 3}

Summary of statistics for the effects of group (with and without LBP), motion phase (forward bending and backward return) and age (40-50, 50-60, and 60-70) on the maximum values of lumbar velocity, deceleration, and acceleration.

\begin{tabular}{|c|c|c|c|c|}
\hline \multicolumn{2}{|c|}{} & $\begin{array}{c}\text { Lumbar } \\
\text { Velocity }\end{array}$ & $\begin{array}{c}\text { Lumbar } \\
\text { Deceleration }\end{array}$ & $\begin{array}{c}\text { Lumbar } \\
\text { Acceleration }\end{array}$ \\
\hline \multirow{2}{*}{ Group } & $F$ & 7.08 & 6.84 & 2.88 \\
\cline { 2 - 5 } & $p$ & $\mathbf{0 . 0 1 2}$ & $\mathbf{0 . 0 1 4}$ & 0.100 \\
\hline \multirow{2}{*}{ Age } & $F$ & 1.89 & 1.50 & 1.13 \\
\cline { 2 - 5 } & $p$ & 0.168 & 0.238 & 0.337 \\
\hline \multirow{3}{*}{$\begin{array}{c}\text { Motion phase } \\
\text { Group } \times \text { Age }\end{array}$} & $F$ & 8.81 & 13.19 & 2.69 \\
\cline { 2 - 5 } & $p$ & $\mathbf{0 . 0 0 6}$ & $\mathbf{0 . 0 0 1}$ & 0.111 \\
\cline { 2 - 5 } & $p$ & 0.30 & 0.34 & 0.56 \\
\hline \multirow{2}{*}{$\begin{array}{c}\text { Group } \times \text { Motion } \\
\text { phase }\end{array}$} & $F$ & 1.49 & 2.04 & 9.76 \\
\cline { 2 - 5 } & $p$ & 0.231 & 0.163 & $\mathbf{0 . 0 0 4}$ \\
\hline \multirow{2}{*}{$\begin{array}{c}\text { Age } \times \text { Motion } \\
\text { phase }\end{array}$} & $F$ & 2.83 & 1.95 & 4.64 \\
\cline { 2 - 5 } & $p$ & 0.074 & 0.159 & $\mathbf{0 . 0 1 7}$ \\
\hline $\begin{array}{c}\text { Group } \times \text { Age } \times \\
\text { Motion phase }\end{array}$ & $F$ & 2.86 & 6.86 & 4.37 \\
\cline { 2 - 5 } & $p$ & 0.072 & $\mathbf{0 . 0 0 3}$ & $\mathbf{0 . 0 2 1}$ \\
\hline
\end{tabular}

Boldface indicates a significant effect 